NASA/CR-2005-213422

\title{
Addressing the Real-World Challenges in the Development of Propulsion IVHM Technology Experiment (PITEX)
}

William A. Maul, Amy Chicatelli, and Christopher E. Fulton Analex Corporation, Brook Park, Ohio

Edward Balaban, Adam Sweet, and Sandra Claire Hayden QSS Group, Inc., Moffett Field, California

Anupa Bajwa

University Affiliated Research Center, Moffett Field, California 
Since its founding, NASA has been dedicated to the advancement of aeronautics and space science. The NASA Scientific and Technical Information (STI) Program Office plays a key part in helping NASA maintain this important role.

The NASA STI Program Office is operated by Langley Research Center, the Lead Center for NASA's scientific and technical information. The NASA STI Program Office provides access to the NASA STI Database, the largest collection of aeronautical and space science STI in the world. The Program Office is also NASA's institutional mechanism for disseminating the results of its research and development activities. These results are published by NASA in the NASA STI Report Series, which includes the following report types:

- TECHNICAL PUBLICATION. Reports of completed research or a major significant phase of research that present the results of NASA programs and include extensive data or theoretical analysis. Includes compilations of significant scientific and technical data and information deemed to be of continuing reference value. NASA's counterpart of peerreviewed formal professional papers but has less stringent limitations on manuscript length and extent of graphic presentations.

- TECHNICAL MEMORANDUM. Scientific and technical findings that are preliminary or of specialized interest, e.g., quick release reports, working papers, and bibliographies that contain minimal annotation. Does not contain extensive analysis.

- CONTRACTOR REPORT. Scientific and technical findings by NASA-sponsored contractors and grantees.
- CONFERENCE PUBLICATION. Collected papers from scientific and technical conferences, symposia, seminars, or other meetings sponsored or cosponsored by NASA.

- SPECIAL PUBLICATION. Scientific, technical, or historical information from NASA programs, projects, and missions, often concerned with subjects having substantial public interest.

- TECHNICAL TRANSLATION. Englishlanguage translations of foreign scientific and technical material pertinent to NASA's mission.

Specialized services that complement the STI Program Office's diverse offerings include creating custom thesauri, building customized databases, organizing and publishing research results ... even providing videos.

For more information about the NASA STI Program Office, see the following:

- Access the NASA STI Program Home Page at http://www.sti.nasa.gov

- E-mail your question via the Internet to help@sti.nasa.gov

- Fax your question to the NASA Access Help Desk at 301-621-0134

- Telephone the NASA Access Help Desk at 301-621-0390

- Write to:

NASA Access Help Desk

NASA Center for AeroSpace Information 7121 Standard Drive

Hanover, MD 21076 
NASA/CR-2005-213422

\section{Addressing the Real-World Challenges in the Development of Propulsion IVHM Technology Experiment (PITEX)}

William A. Maul, Amy Chicatelli, and Christopher E. Fulton

Analex Corporation, Brook Park, Ohio

Edward Balaban, Adam Sweet, and Sandra Claire Hayden

QSS Group, Inc., Moffett Field, California

Anupa Bajwa

University Affiliated Research Center, Moffett Field, California

Prepared for the

First Intelligent Systems Technical Conference

sponsored by the American Institute of Aeronautics and Astronautics

Chicago, Illinois, September 20-22, 2004

Prepared under Contract NAS3-00145

National Aeronautics and

Space Administration

Glenn Research Center 


\section{Acknowledgments}

The authors would like to acknowledge the contributions of all of the other PITEX and NITEX team members at the NASA Kennedy Space Center, the NASA Ames Research Center, and the NASA Glenn Research Center. Their contributions were instrumental in the successful completion of this work. The authors would also like to acknowledge the support and guidance of the NGLT IVHM Project Office managed by the NASA Ames Research Center.

Trade names or manufacturers' names are used in this report for identification only. This usage does not constitute an official endorsement, either expressed or implied, by the National Aeronautics and Space Administration.

This report contains preliminary findings, subject to revision as analysis proceeds.

Available from

NASA Center for Aerospace Information 7121 Standard Drive

Hanover, MD 21076
National Technical Information Service 5285 Port Royal Road Springfield, VA 22100 


\title{
Addressing the Real-World Challenges in the Development of Propulsion IVHM Technology Experiment (PITEX)
}

\author{
William A. Maul, Amy Chicatelli, and Christopher E. Fulton \\ Analex Corporation \\ Brook Park, Ohio 44142 \\ Edward Balaban, Adam Sweet, and Sandra Claire Hayden \\ QSS Group, Inc. \\ Moffett Field, California 94035 \\ Anupa Bajwa \\ University Affiliated Research Center \\ Moffett Field, California 94035
}

The Propulsion IVHM Technology Experiment (PITEX) has been an on-going research effort conducted over several years. PITEX has developed and applied a model-based diagnostic system for the main propulsion system of the X-34 reusable launch vehicle, a space-launch technology demonstrator. The application was simulation-based using detailed models of the propulsion subsystem to generate nominal and failure scenarios during captive carry, which is the most safety-critical portion of the X-34 flight. Since no system-level testing of the X-34 Main Propulsion System (MPS) was performed, these simulated data were used to verify and validate the software system. Advanced diagnostic and signal processing algorithms were developed and tested in real-time on flight-like hardware. In an attempt to expose potential performance problems, these PITEX algorithms were subject to numerous real-world effects in the simulated data including noise, sensor resolution, command/valve talkback information, and nominal build variations. The current research has demonstrated the potential benefits of model-based diagnostics, defined the performance metrics required to evaluate the diagnostic system, and studied the impact of real-world challenges encountered when monitoring propulsion subsystems.

\section{Introduction}

For several years researchers at NASA's Glenn Research Center, Ames Research Center, and Kennedy Space Center have been engaged in a cooperative effort to develop and demonstrate an advanced diagnostic capability for a space-based propulsion application. This effort, called the Propulsion Integrated Vehicle Health Management (IVHM) Technology Experiment (PITEX), was a key element of the Northrop Grumman Corporation Space Launch Initiative Risk Reduction Task, and the cornerstone of their IVHM Vehicle Test Bed demonstration at the Jet Propulsion Laboratory. ${ }^{1}$ The PITEX research was based on legacy work from the NASA IVHM Technology Experiment for X-Vehicles (NITEX), funded through the Future-X Program Office. NITEX was selected to fly on the X-34 Reusable Launch Vehicle (RLV) developed by Orbital Sciences Corporation (OSC). The intent of this research was to extend IVHM technologies by applying them to pertinent RLV subsystems. The NITEX research initially focused on the X-34 Main Propulsion System (MPS) during all phases of operation. ${ }^{2,3}$ The research was scaled back to address X-34 MPS subsystems active during Captive Carry because, during this phase, critical failures would endanger humans involved in the vehicle testing.

After the X-34 program was cancelled, PITEX carried forward the previous research by building upon a prototype diagnostic system that was developed during the NITEX period. The PITEX research focused on the continued maturation of diagnostic technologies as applied to subsystems relevant to 2nd Generation RLVs and in particular, the X-34 MPS. These diagnostic technologies were aimed at real-time 
safety applications, and therefore the PITEX demonstration required the establishment of metrics to assess the real-time diagnostic performance in terms of accuracy, speed, and computer resources. Subsequent improvements to the PITEX software have been quantified by these metrics and reported previously. ${ }^{4,5}$

For any diagnostic system, demonstration and validation are difficult to perform, because in order to determine that the diagnostic system is functioning properly, the monitored system must fail. Ideally, testing of the diagnostic system would occur directly on the hardware it was designed to monitor. However, the costs and risks associated with these types of failure tests are prohibitive, especially for rocket propulsion systems. To overcome this problem, simulation-based testing and validation of diagnostic systems must become an acceptable process. Due to the early cancellation of the X-34 program, PITEX development and testing relied solely on simulated data and exposed the importance of simulation-based testing and the level of realism that testing must provide.

Real-world challenges encountered in the development of PITEX and how they were managed are the focus of this paper. Primarily, the lack of experimental data for development, testing, and validating the diagnostic system and its robustness to system uncertainties and variations are addressed. In addition, improvements to the development process for the diagnostic model are also identified. This paper is organized as follows. A description of the PITEX real-time demonstration is provided next. The software and hardware used, as well as the domain application and the test scenarios, are defined. After that, realistic sensor and hardware challenges encountered in developing the PITEX diagnostic system are reviewed, and recent enhancements implemented to address these challenges are presented. Finally, impacts on the PITEX demonstration test results, as a byproduct of incorporating these changes, are reported and discussed in the context of validating the diagnostic solution and the management of computer resources.

\section{PITEX Demonstration Overview}

The PITEX demonstration system architecture is based on the overall NITEX flight experiment architecture and is designed to test a subset of software components from the original architecture. The demonstration system features simulated propulsion data being processed by diagnostic software on the "flight-like" Real-Time Ground Unit (RGU) and display software hosted on a Ground Processing Unit (GPU).

\section{A. Hardware Specifications}

The PITEX diagnostic software resides on a Radstone PPC4A-750 VME single Board Computer. The card is housed in a chassis with a VME backplane and a SCSI hard drive. I/O ports provide both serial and Ethernet accessibility to the card. The PITEX diagnostic software is compiled in the Tornado II VxWorks (release 5.4) environment using the $\mathrm{C}$ and $\mathrm{C}++$ compilers supplied with VxWorks. The VxWorks kernel is based on the Radstone board support package, release 1.2/1.

The GPU hardware is a Pentium III based computer, with the clock speed of $550 \mathrm{MHz}, 256 \mathrm{MB}$ of RAM, and 30 GB of hard disk storage. The GPU software has been successfully compiled and run using the gcc compiler on Redhat Linux versions 6.2, 7.3, and 9.0. The GPU communicates with the RGU through a TCP/IP Ethernet connection. 


\section{B. Software Specifications}

The software components of the PITEX demonstration system consist of an MPS simulator, Telemetry Input System (TIS), Monitor software, Real-Time Interface (RTI), Livingstone inference engine $^{6}$ (which uses a compiled qualitative model of the MPS), Results Output System (ROS), and the GPU. The overall architecture is shown in figure 1. The virtual propulsion system simulates the flight-like sensor data associated with the particular mission phases within the nominal and failure scenarios. These data are stored in binary files prior to diagnostic system testing. The TIS reads these data sets and incrementally stores the information so as to provide access to the modules in the same manner and time frame as what was to be experienced by the system during the real-time operations on an actual test flight. After the TIS stores the data on-line to simulate a data sweep, the data are accessed by the Monitor software where pertinent features of the propulsion system are extracted and transformed into qualitative information. This information is then passed through the RTI to Livingstone, where system-level diagnostics are performed using a high-level qualitative model. The diagnostic output is collected by the ROS and sent to the GPU for display. Each of these software modules is described in greater detail in reference 4 .

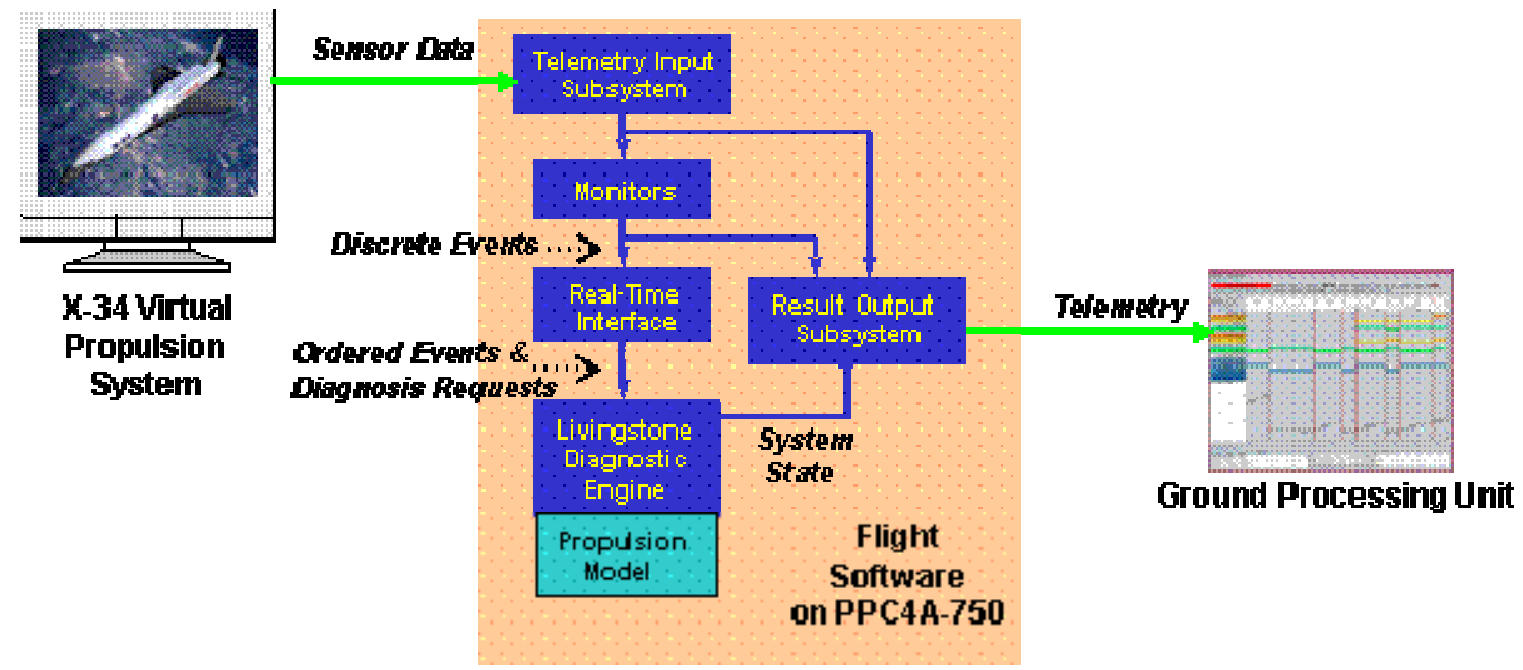

Figure 1.-PITEX Demonstration Architecture.

\section{Domain Application}

The PITEX development and testing has focused on the X-34 MPS during the Captive Carry phase of operation. The portion of the X-34 MPS modeled for PITEX was restricted to the liquid oxygen (LOX) and standard kerosene rocket fuel (RP-1) propellant feed circuits and the supporting pneumatic and hydraulic systems. The Captive Carry phase is the flight period where the X-34 vehicle, while attached to an L1011 aircraft, departs from the tarmac and ascends to 38,000 feet where it is released for flight. During this period of time, which is approximately 2.5 hours, the MPS maintains the cryogenic LOX propellant in a stable state through a conditioning process. Then it prepares the engine for flight, introducing LOX and RP-1 propellant into the feed lines. A timeline of these events is presented in figure 2. 

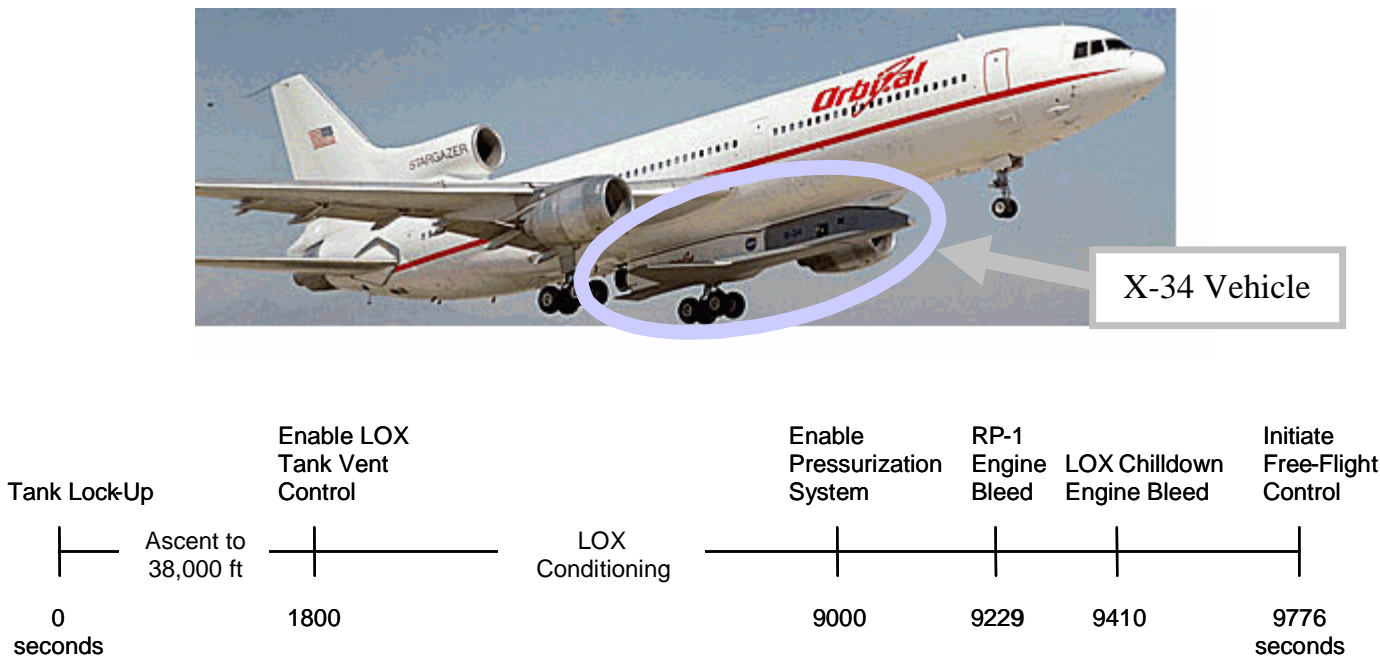

Figure 2.-X-34 Captive Carry Design Reference Mission.

PITEX was developed to detect and isolate certain fault modes and utilized 25 distinct scenarios to demonstrate its diagnostic capabilities. Twenty-four of these scenarios were selected based on the Failure Modes and Effects Analysis of the X-34 MPS, input from domain experts, and the feasibility of simulating the failure on the ground. Brief descriptions of the scenarios and their corresponding fault injection times (associated with the timeline shown in figure 2) are listed in table 1. Figure 3 is a schematic of the X-34 MPS that shows the location of the components along with the sensors available for diagnostics. As noted in table 1, for some components more than one failure mode is considered, and there can be some confusion about the failure descriptions. For instance, there is a difference between a valve sticking closed and failing closed. In the former case, the valve "sticks" closed when it has been commanded to open but remains closed. In the latter case, the valve "fails" closed when it should remain open but closes without command. Analogous descriptions apply to valves sticking open and failing open.

TABLE 1.-PITEX DIAGNOSTIC DEMONSTRATION SCENARIOS

\begin{tabular}{|c|l|l|}
\hline \multicolumn{1}{|c|}{} & \multicolumn{1}{|c|}{ Description } & \multicolumn{1}{|c|}{$\begin{array}{c}\text { Fault } \\
\text { Injection } \\
\text { Time } \\
\text { (seconds) }\end{array}$} \\
\hline & Nominal data set & N/A \\
\hline 1 & LOX Feed Valve, PV03, sticks closed & 9410 \\
\hline 2 & LOX Feed Servo Valve, SV33, fails closed & 9539.79 \\
\hline 3 & LOX Tank Vent Relief Servo Valve, SV31, sticks open & 2706.9 \\
\hline 4 & LOX Tank Vent Relief Servo Valve, SV31, fails open & 5000 \\
\hline 5 & LOX Tank Vent Relief Valve, VR01, sticks open & 2706.9 \\
\hline 6 & LOX Tank Vent Relief Valve, VR01, fails open & 5000 \\
\hline 7 & LOX Tank Vent Relief Servo Valve, SV31, sticks closed & 5167.4 \\
\hline 8 & LOX Tank Vent Relief Servo Valve, SV31, fails closed & 3331 \\
\hline 9 & LOX Tank Vent Relief Valve, VR01, sticks closed & 5167.4 \\
\hline 10 & Pressurization Regulator, RG11, regulates high & 9000 \\
\hline 11 & Pressurization Regulator, RG11, regulates low & 9642.67 \\
\hline 12 & LOX Tank Pressurization Valve, SV03, sticks open & 9735.29 \\
\hline 13 & LOX Tank Pressurization Valve, SV03, sticks closed & 9766.05 \\
\hline 14 & The open microswitch, MMSW205X, fails on the LOX vent/relief solenoid valve, SV31 & 3301.7 and \\
\hline
\end{tabular}




\begin{tabular}{|l|l|l|}
\hline & \multicolumn{1}{|c|}{ Description } & \multicolumn{1}{|c|}{$\begin{array}{c}\text { Fault } \\
\text { Injection } \\
\text { Time } \\
\text { (seconds) }\end{array}$} \\
\hline & \multicolumn{1}{|c|}{} & 7260.8 \\
\hline 15 & The close microswitch, MMSW213X, fails on the LOX feed valve, PV03 & 9410 \\
\hline 16 & The RP-1 feed valve, PV02, fails closed after the RP-1 bleed has been initiated & 9359 \\
\hline 17 & The RP-1 vent/relief pneumatic valve, VR06, fails open & 9379 \\
\hline 18 & The primary RP-1 tank pressurization valve, SV02, sticks closed & 9383.86 \\
\hline 19 & The primary RP-1 tank pressurization valve, SV02, sticks open & 9384.71 \\
\hline 20 & The open microswitch, MMSW205X, fails on SV31, after that, SV31 fails closed & 3301.7 \\
\hline 21 & GHe pressurization system pressure regulators, RG11 and RG01, both regulate high & 9000 \\
\hline 22 & Two of the LOX vent line pressure sensors, MPRE202P and MPRE212P, fail high & 0.0 \\
\hline 23 & Two of the LOX vent line pressure sensors, MPRE202P and MPRE212P, fail low & 0.0 \\
\hline 24 & The last lower flapper valve in the aft LOX tank fails shut & 9199 \\
\hline
\end{tabular}

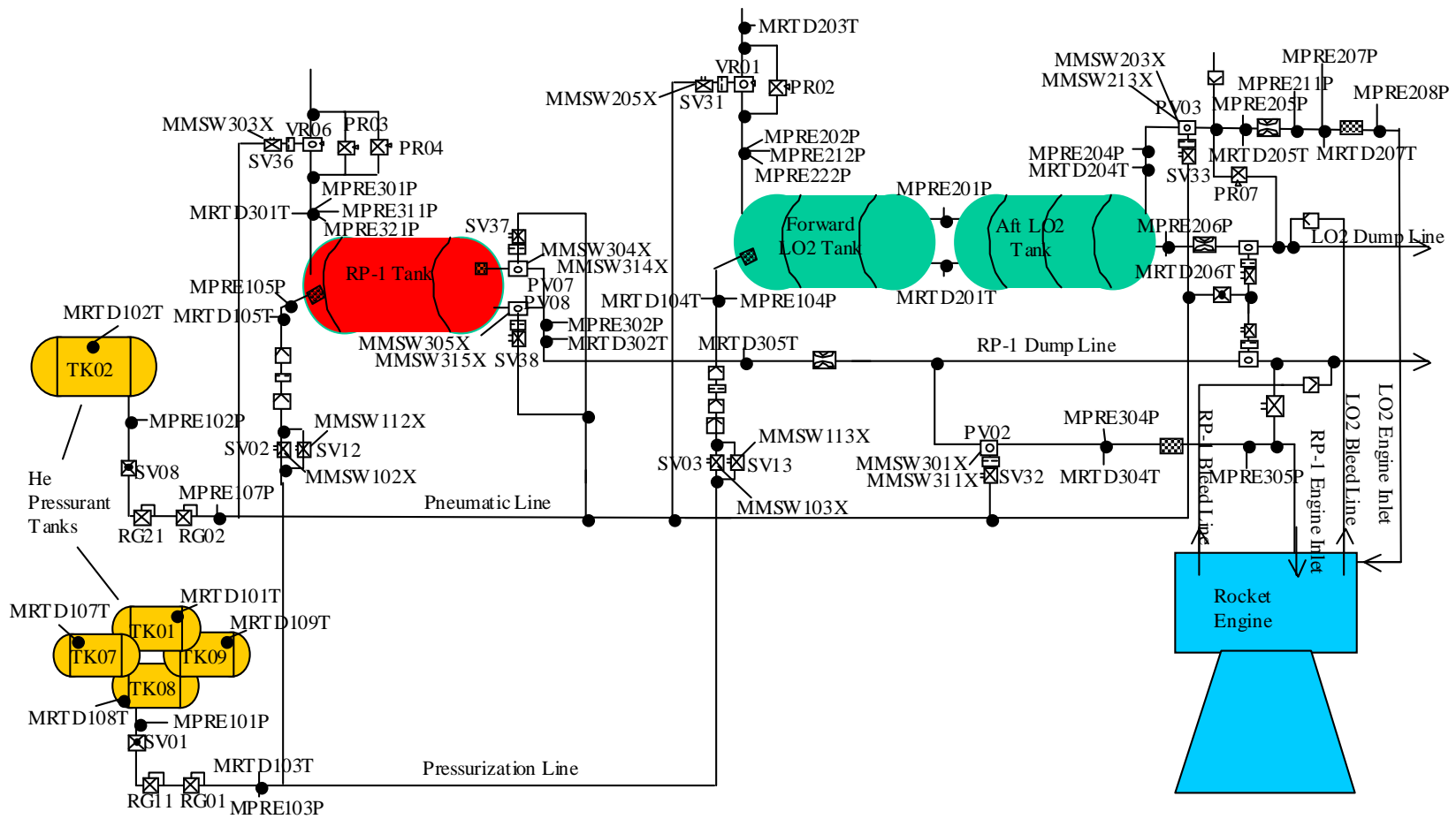

Figure 3.—PITEX X-34 Main Propulsion System Schematic.

\section{PITEX Development Challenges}

A key challenge that any diagnostic system must face is the ability to handle real-world uncertainty and variances that naturally occur, while at the same time providing sensitivity with respect to detecting and recognizing anomalous conditions. Consequently, one of the key activities of the PITEX research was to expose the diagnostic software to various real-world effects. The purpose of this was to determine whether the current system was robust to these effects and if not, how those effects could be addressed 
within the diagnostic solution. Another goal was to lay the groundwork for a well-designed diagnostic modeling environment. The objective of this is to reduce the life cycle costs (LCC) (costs of development, maintenance, testing, and validation) of the diagnostic solution. The remainder of this section will describe the real-world effects (sensor and hardware uncertainties) and Livingstone diagnostic modeling changes that were addressed during the development of PITEX.

\section{A. Sensor Uncertainties}

One of the primary difficulties in fault detection and diagnosis is the ability of the diagnostic software to discern what is actually occurring in the system from the sensor information. The sensor signal contains a varying level of noise that is unrelated to the physical state of the monitored system and is superimposed upon the actual signal. The diagnostic system must be conservative in its determination of the actual sensor signal in order to ensure that the observation is truly a representation of the physical system and not merely a product of sensor noise or sensor failure. At the same time, the diagnostic system must be sensitive enough to provide a timely assessment of the system health that will enable remediation in the event of a fault condition.

Another important sensor information consideration is the analog-to-digital (A/D) resolution. The $\mathrm{A} / \mathrm{D}$ resolution is based on the amount of digital information retained for each sensor and establishes the ability to distinguish system events from the sensor signal. The resolution is a function of the dynamic range and the digital word size allocated to that sensor during the A/D conversion process. The resolution defines the smallest voltage change that can be measured by the AD converter; as the A/D resolution decreases (the resolution value becomes larger), the ability of the sensor signal to be used to distinguish changes decreases. Each sensor may have a unique resolution associated with it. This complicates the problem when a diagnostic algorithm is attempting to cross-correlate events in related sensors that have different resolutions.

\section{B. Hardware Uncertainties}

The performance of a system is based upon the interactions of the subcomponents and the external boundary conditions. There are variations that manifest themselves in the data that are not indicative of a system fault, but they are caused by hardware component differences or changes in the system's boundary conditions. Some of these uncertainties include: variations in the actuation time for the opening or closing of valves, regulator set points, initial conditions for the propellant tank, boundary conditions for the dump lines, and the atmospheric conditions. These types of variations are considered normal and must be taken into account when establishing the threshold limits that the diagnostic system is using to detect actual system events. Furthermore, the diagnostic system must demonstrate the capability to process these nominal system variations without any false alarms.

Time delays in the system can also be attributed to hardware uncertainties. In mechanical or fluid systems, more so than an electrical system, there are inherent delays in physical properties to system changes. The reaction times of electrical switches or indicators are virtually instantaneous. Moving mechanical components however, such as a valve, often require tens to hundreds of milliseconds to completely open or close. In addition, there are physical delays in the system that also must be taken into account. For a fluid system there is a period of time that the system will be in an unsteady state. The length of this transient period is different depending on the initial state and disturbances to the system and is further complicated by the presence of any faults. Correlating all of these variations in real time can be a difficult process. The diagnostic system must handle all these types of delays, ensuring that all pertinent information is available before an analysis on the observations is performed, while at the same time providing a responsive and timely analysis. 


\section{Diagnostic Modeling Environment}

The ease at which a diagnostic system can be developed is important when the goal is to reduce the development time and overall LCC for a new application. Toward that end, being able to reuse component modules for previously developed and verified systems is an important capability to develop. Presently, each component in the Livingstone model must be defined individually, and this can be cumbersome and time consuming for a complicated system such as the X-34 MPS. For instance, similar components, such as solenoid valves, have different models depending on their placement in the system. To simplify this process, a more robust diagnostic modeling environment is required. One method is to use a single valve component type that has the same basic underlying logic and thus is generic to implement. Modifying the diagnostic model to use these generic representations instead of specialized components for each instantiation would save development and testing time when creating the diagnostic model. As another benefit, the Livingstone development environment becomes a library of components that can be utilized for other applications and facilitates interoperability with other diagnostic systems.

\section{PITEX Developments and Enhancements}

This section will outline the modifications that were implemented in PITEX as part of that research effort to address the issues of sensor and hardware uncertainties. In addition, an overview of the generic component development for the Livingstone diagnostic modeling environment is also presented.

\section{A. Modifications to Address Sensor Uncertainties}

Initial versions of the PITEX software used thresholds to divide the response space of a sensor signal or processed signal into distinct qualitative regions. These regions were predefined based on anticipated system responses to various conditions. The PITEX Monitor software assessed the sensor signal to determine where it lies in the response space and maintained an array of recent qualitative assignments that were polled to determine what observations to report to the RTI. There were three problems with this method.

1. Potentially, narrow regions within the divided response space could be skipped and therefore not reported.

2. The process was based upon predefined variables and was therefore sensitive to dynamic variations in sensor outputs such as noise levels.

3. This technique was insensitive to slowly varying process changes and required large latency windows, on the order of 20 seconds, to compensate for the inability to detect and resolve the slow response.

To solve these problems, a statistically-based algorithm was developed that would gather a population of the data, determine the mean and uncertainty of that population, and report all the regions that are overlapped by the population's distribution. This version of PITEX addressed each of the problems previously mentioned by allowing the software to dynamically determine the uncertainty of the signal due to sensor noise and reflect that uncertainty into the observations passed on to the diagnostic model. The use of this approach reduced latency windows to approximately 6 seconds for the slow varying processes. Even with this modification, another issue still remained, that is the potential for "observation chatter" where the same sets of observations were constantly repeated. The chatter occurred when the sensor signal neared a threshold and the diagnostic system was required to respond to each set of observations. The frequent calls to perform diagnoses resulted in the consumption of valuable computer resources. To 
resolve this issue, the policies within the RTI were modified to recognize this condition and eliminate repetitive diagnostic requests.

The PITEX solution also addressed the issue of sensor resolution. For the X-34 MPS system there were several flow-field sensors that were correlated within the diagnostic system, but they were not at the same level of sensitivity or resolution. Since the essential information for determining a sensor's resolution (i.e., memory storage and measurable range) is known a priori, a modification was made to the Monitor software to add the uncertainty due to sensor resolution to the observation, thereby enabling the cross-correlation of sensors with differing sensitivities.

\section{B. Modifications to Address Hardware Uncertainties}

Varying physical response times was an issue that was addressed by PITEX in order to reduce diagnostic times and increase diagnostic coverage. The primary constraint imposed by the Livingstone diagnostic engine was that it receives quasi-steady state information. Therefore, transient, dynamic information had to be filtered from the diagnostic process. Aside from the loss of key diagnostic information that may be contained within the transient period, this created a time delay where the PITEX system was forced to be dormant. These dormant periods, when the physical system is reaching steady state conditions, were defined as the physical latency periods. The times associated with these periods were determined empirically for various nominal system responses and constituted the majority of the overall diagnostic delays. In order to shorten the diagnostic delay, two key capabilities were added to the RTI which enhanced the ability of the PITEX to perform analysis during the transient periods.

1. The first was the ability to temporarily suspend only those observations directly impacted by the observed event or command. This allows the diagnostic system to continue to monitor unrelated areas of the system without increasing the chance of misdiagnosis by using an unsettled observation.

2. The second was the assignment of pre-set latencies that are both sensor and event specific. This enables diagnostic analysis with only a subset of observations available. This may provide a faster diagnostic response, however it is tempered by the fact that the diagnosis is based on incomplete information.

Additional work was conducted to expand the diagnostic coverage of Livingstone to transient regions. ${ }^{5}$ In this new approach, a prototype of an event-specific transient monitor was designed and developed to provide an exact indication of when a transient event is completed. These changes may allow PITEX to provide diagnoses faster with complete available information and also potentially enable the inclusion of transient constraints to the Livingstone diagnostic models. These modifications to the reduced-prototype diagnostic model, demonstrated that Livingstone could provide diagnoses not only during steady sate, but also during the latency periods.

\section{Modifications to the Diagnostic Modeling Environment}

In order to reduce the development time of the diagnostic system, the modification of the diagnostic modeling environment focused on establishing generic modeling components. A new Livingstone model generation tool, called Oliver, was developed to utilize the generic components. As a demonstration of the potential application of generic component within Livingstone, the solenoid valves, sensors, and regulators of the X-34 MPS were selected as components for conversion to a generic format. For each component, model information was separated into two categories: that part specific to the X-34 MPS and the part generic to the component. The generic information was placed in a generic component module. In the future, when a specific module is needed, the generic component module can be extracted from a library and used as a framework to create the specific application. Examples of these new generic 
components (solenoid valves, sensors, and regulators) were generated and incorporated into the genericderived prototype PITEX model. ${ }^{7}$

\section{Testing Results}

In general, the overall testing and demonstration of PITEX with the modifications that were described in the preceding section were conducted in two phases: (1) diagnostic validation and (2) computer resource utilization.

\section{A. Diagnostic Validation}

During the diagnostic validation phase, each scenario from table 1 was processed by the PITEX software and the resulting diagnostic output was analyzed. The potential fault candidates selected by PITEX were compared to the injected fault. Each candidate had to be justified and resolved based on the available commands and observations of the system. The following validation criteria were used in evaluating the diagnosis:

- The injected fault was among the fault candidates reported.

- All candidates in the diagnosis are explainable given the evidence available.

In addition, the following acceptance criteria were used:

- A diagnosis of a potential fault was obtained some time after the fault is injected.

- Once the injected fault was diagnosed, it was in the list of candidates for the duration of the scenario. Note, that the injected fault may not have the highest rank in the list of candidates.

Table 2 shows a sample of the diagnostic output from this validation testing for fault scenario number two. The fault injection time is the time in the simulation profile where the failure occurs. The diagnostic time is the initial time, following the injected fault, when the PITEX software provides diagnostic analysis output. With each diagnostic output PITEX provides a list of candidate solutions that could explain the available system observations. The highlighted candidate indicates the injected failure. The rank value is an internal metric within the diagnostic model that is generated from the order of magnitude of the probability of fault occurrence and would be the basis for diagnostic result selection.

TABLE 2.-SAMPLE OF PITEX VALIDATION OUTPUT

\begin{tabular}{|c|c|l|c|}
\hline $\begin{array}{c}\text { Fault Injection } \\
\text { Time (seconds) }\end{array}$ & $\begin{array}{c}\text { Diagnostic Time } \\
\text { (seconds) }\end{array}$ & \multicolumn{1}{|c|}{ Candidate Solutions } & Rank \\
\hline \multirow{5}{*}{9539.79} & 9544.40 & LOX Feed Servo Valve, SV33, Stuck Closed & 1 \\
\cline { 3 - 4 } & & LOX Feed Valve, PV03, Stuck Closed & 1 \\
\cline { 3 - 4 } & & LOX Feed Servo Valve, SV33, Unknown Fault & 2 \\
\cline { 3 - 4 } & LOX Feed Valve, PV03, Unknown Fault & 2 \\
\cline { 3 - 4 } & $\begin{array}{l}\text { LOX Feed Valve, PV03, Close MicroSwitch Faulty } \\
\text { LOX Feed Valve, PV03, Open MicroSwitch Faulty }\end{array}$ & 3 \\
\cline { 3 - 4 } & \multirow{5}{*}{9550.0} & LOX Feed Servo Valve, SV33, Stuck Closed & 1 \\
\cline { 3 - 4 } & & LOX Feed Valve, PV03, Stuck Closed & 1 \\
\cline { 3 - 4 } & LOX Feed Servo Valve, SV33, Unknown Fault & 2 \\
\cline { 3 - 4 } & & LOX Feed Valve, PV03, Unknown Fault & 2 \\
\hline
\end{tabular}

It is important to note that the PITEX diagnostic solution does not always generate a single candidate solution. For a set of observations, there will always be a list of possible solutions. This list of solutions, 
called the ambiguity set, can be prioritized based on criticality and probability of occurrence. In the case where a specific failure needs to be distinguished from the remaining set, because the mitigating responses are drastically different, this would indicate or highlight where additional system information is required. The additional information may be in the form of additional sensors or more advanced processing of the current sensor suite. Also note, for the example fault scenario in table 2, the original candidate set evolves slightly in time. This is because as system observations become more refined in time, the diagnostic solution will become more focused.

For the basic PITEX testing, all of the data sets that represent the fault scenarios from table 1 passed the validation testing as defined in the beginning of this section. In addition, in the list of candidate solutions for most of the failure scenarios, the top-ranked fault is the injected fault. The only exceptions to this are for fault scenarios 21 and 24. In fault scenario 21, two regulators in the pressurization system fail high. Because the likelihood of a double regulator fault is less than the pressurization sensor in that same line failing, the diagnostic system ranks the latter as more likely to occur. Likewise for fault scenario 24, the lower flapper valve in the aft LOX tank is not the most probable fault, and based on the diagnostic information there is no way to determine that it should be the highest ranked fault.

Diagnostic timing is defined as the time interval beginning at the time the fault can be sensed to the time the diagnosis is reported. The sensed time is not necessarily the time of the fault. For example, the fault may be that a valve is stuck in the open position, but the failure would not be observable until the next time the valve is commanded closed. For all of the PITEX analysis, the fault injection and sensed fault times are assumed to be the same, therefore, the diagnostic delay time of the sample output in table 2 is 4.61 seconds. Figure 4 illustrates the changes in diagnostic delay because of the PITEX modifications. The average diagnostic time for all the scenarios was 8.21 seconds with a maximum delay of 27.44 seconds. The decrease in diagnostic time (20 second average delay to approximately 8 seconds) was a combined result of the statistically-based monitor algorithm and the modified RTI policies.

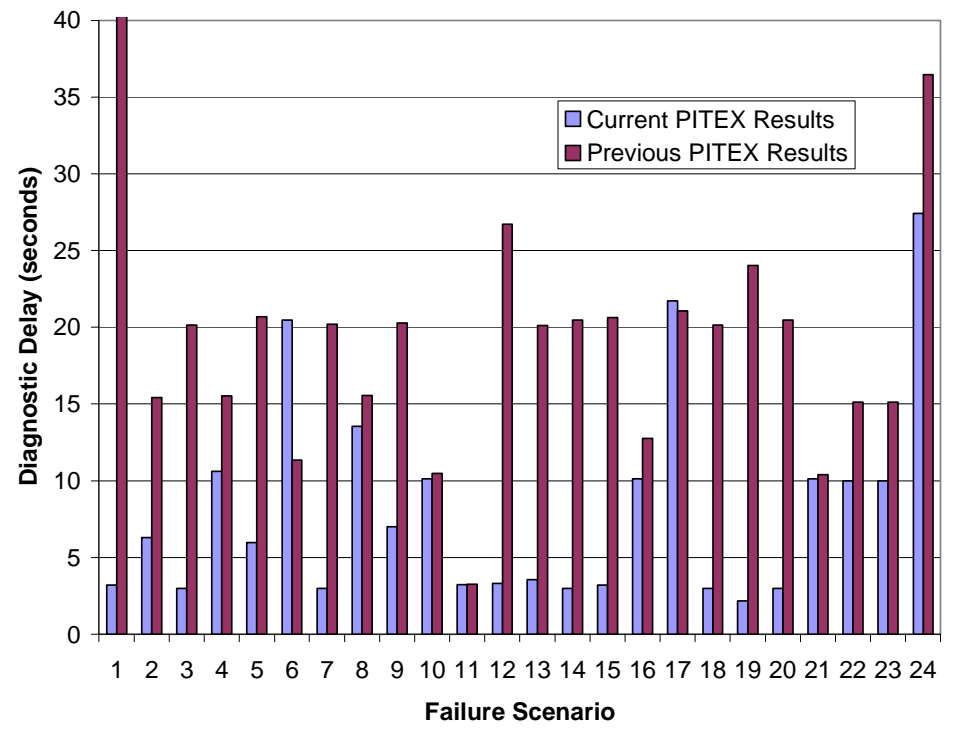

Figure 4.-Comparison of the Diagnostic Delay Output from Previous Version of PITEX and the Current PITEX Software.

The PITEX testing also included a study of the impact of sensor resolution upon the diagnostic output. During this testing phase, simulation data was utilized that contained the sensor resolution information for each sensor signal. In all but one case, the diagnostic solution passed the validation testing. In the case where the validation testing failed, PITEX had rescinded the correct fault analysis at a time over 500 seconds after the original fault indication was made. The root cause was a set of 
observations that caused PITEX to retract the original fault analysis and indicate no failure had occurred. In this case, the insensitivity of several of the sensors involved in the analysis combined with the extended failure condition caused the confusion.

It was found that the impact of the sensor resolution on the diagnostic delay times depended on the scenario tested. In several cases, the diagnostic delay increased indicating that parameters utilized in the analysis required improved sensor resolutions. By considering the impact of design parameters, such as sensor resolution, on the diagnostic analysis, trade studies can be conducted to determine cost of design change and increase in diagnostic performance.

An investigation of the hardware build variation impact on the diagnostic performance of PITEX was also conducted. The RP-1 subsystem was used to evaluate the robustness of the diagnostic system to specific component variations. Uncertainties were systematically introduced in the simulated data sets by varying four key parameters based on information obtained from OSC.

1. Setpoint for the primary regulator in the pressurization system (RG11)

2. Opening time for the RP-1 tank feed pneumatic valve (PV07)

3. Opening time for the RP-1 feed pneumatic valve (PV02)

4. Opening/closing times for the RP-1 tank primary pressurization valve (SV02)

Using a Design of Experiment (DOE) methodology, ${ }^{8}$ twenty-three test data sets were selected and generated, representing the range of nominal variation for these hardware components. Some false alarms were detected when these data sets were processed. However, since PITEX was initially developed without the hardware information, these false alarms were not unexpected. Adjustments to the threshold values in the monitor initialization file and in the diagnostic model corrected the problem. This initial study indicated further DOE analysis will need to be conducted over the entire monitored system to ensure that hardware variations are accounted for within the diagnostic analysis.

With the adjusted monitor thresholds, all twenty-four PITEX failure scenarios were reprocessed. With one exception, all of the data sets that represent the fault scenarios from table 1 passed the validation testing. The one case that did not pass (failure scenario number 21) was a result of the original failure scenario not being severe enough. In that failure scenario, the primary pressurization regulator failed its high pressure limit. From the hardware uncertainty studies conducted for this component, the allowable nominal set point pressure range for this regulator encompassed the original failure value; therefore the final PITEX diagnostic solution did not result in the proper detection of this failure.

\section{B. Computer Resource Utilization}

The second phase of the PITEX testing involved the assessment of the performance of the diagnostic software on "flight-like" hardware. Performance metrics evaluated were CPU usage and memory utilization. These were selected due to their influence on the real-time operation of the diagnostic system.

Overall, the CPU usage was very low. The exception to this was when Livingstone performed a diagnosis. The RTI requests a diagnosis from Livingstone only when conditions in the system indicate that a fault has occurred, so the impact to the CPU usage was minimal since Livingstone is called so infrequently. In addition, Livingstone has a low execution priority and therefore, the execution of other time critical processes is not inhibited. If CPU usage did reach $100 \%$ that would simply result in a longer time before a diagnosis was produced. It would not prevent PITEX from detecting a failure. The ability of PITEX to perform during periods of limited computer resources was previously demonstrated in earlier CPU restriction tests. ${ }^{4}$

For the memory utilization tests, static, stack, and dynamic memory usage were examined. PITEX demonstrated that it effectively uses all three. The memory tests demonstrated that PITEX performed well within the current memory constraints of the hardware design. The largest consumer of the available memory was Livingstone (which also included the RTI for testing purposes). However, as illustrated in figure 5, approximately $70 \%$ of the memory resources are still available after accounting for the diagnostic system. This demonstrated the expansion potential of the PITEX diagnostic system. 


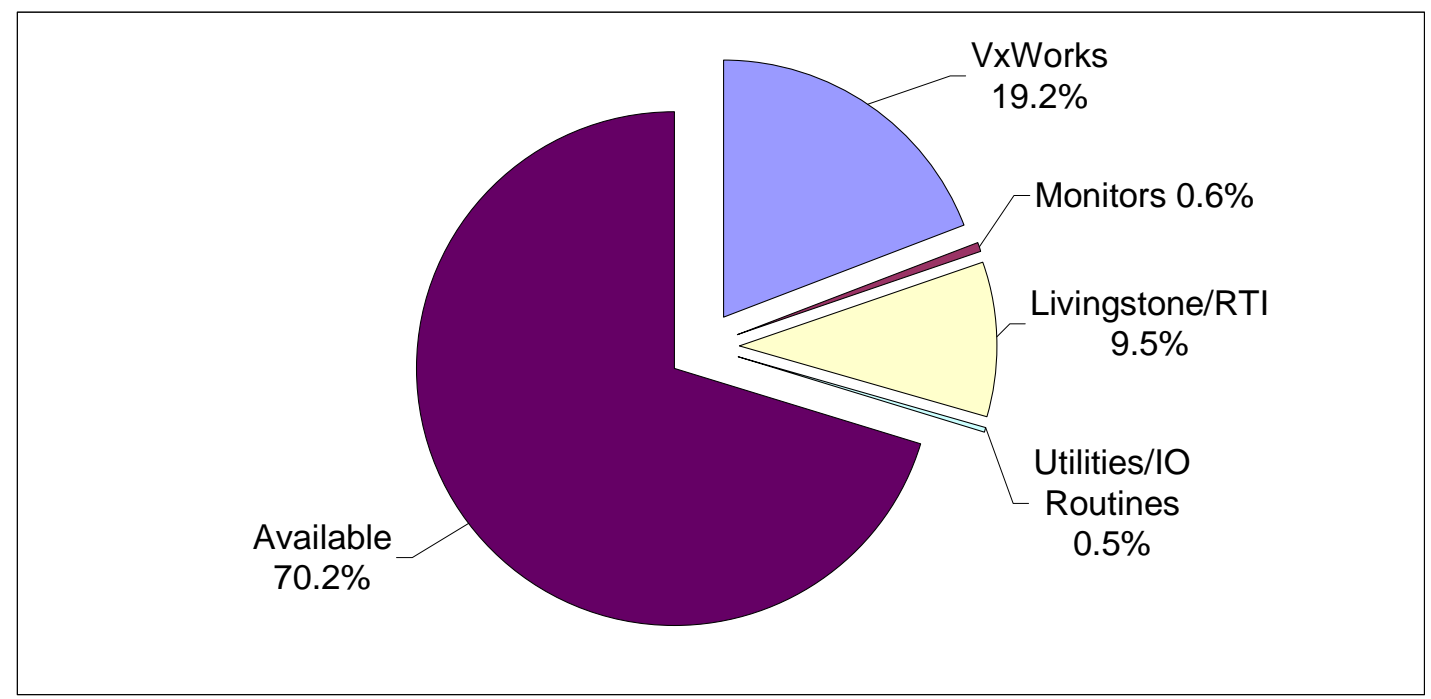

Figure 5.-Current Memory Usage Chart for PITEX X-34 MPS Application.

\section{Concluding Remarks}

In general, there are few applications and demonstrations of on-board real-time diagnostics for problems that represent the complexity and uncertainty of space transportation or launch systems. To address this technology gap, the Propulsion IVHM Technology Experiment (PITEX) developed and applied a diagnostic/health assessment system for the X-34 main propulsion system (MPS), a relevant 2nd Generation reusable launch vehicle (RLV) subsystem. As reported in this paper, problems relating to the lack of experimental data and the diagnostic system's robustness to system variations were resolved during the development of PITEX. By considering flight-like data (noise, sensor resolution, and hardware uncertainties), realistic nominal and failure modes, real-time operation, and computer resource management issues, PITEX demonstrated that it was a "real" solution for the health assessment of a rocket propulsion system. Furthermore, improvements to the Livingstone diagnostic modeling environment were demonstrated with the PITEX application.

Ideally, experimental data would have provided the nominal and failure data required to demonstrate and validate the diagnostic system. However due to the unavailability, costs, and risks associated with these types of flight tests, that was not possible. Failure data is too costly to gather for rocket propulsion systems and unavoidably prohibitive to collect. Therefore, flight-like data were used and the limitations associated with a simulated environment were circumvented by including as much real-world information as possible in the data. Together, the flight-like data and failure scenarios provided a complete simulationbased testing, demonstration, and validation environment for PITEX. Ultimately the certification of health assessment tools and systems, particularly for rocket propulsion systems, will require extensive simulation-based testing.

PITEX demonstrated the capability to do reliable diagnostics in the presence of real-world system variations and uncertainties by detecting and isolating, at the subsystem level, injected faults correctly. In addition, realistic failure modes were utilized based on information obtained from X-34 domain experts at Marshall Space Flight Center (MSFC) and Orbital Sciences Corporation (OSC). These failure modes were considered critical to the operation of the X-34 MPS and included valves sticking/failing open or closed, regulator problems, and sensor and microswitch failures. In addition, the type of testing performed on PITEX was unique. Along with the validation of the diagnostic solution, the risks to hardware and safety concerns were handled by quantifying resource management needs and performance under CPU restrictions. Analysis indicated that the PITEX system used fewer resources than were allocated for the 
computation of the diagnostic solution, indicating that the diagnostic system could be expanded to cover additional components. This in-depth testing advanced the PITEX solution, from a simple laboratory environment demonstration to a more relevant environment tested tool.

\section{References}

${ }^{1}$ James, M., Baroth, E., Mellinger, L., Park, H., Stough, T., Brown, S.A., Meyer, C.M., "Integrated Vehicle Test Bed for IVHM Systems on 2nd Generation RLV,”, IEEE Aerospace Conference, Big Sky, Montana, March 2003.

${ }^{2}$ Sgarlata, P., and Winters, B., “X-34 Propulsion System Design,” 33rd AIAA/ASME/SAE/ASEE Joint Propulsion Conference and Exhibit, July 6-9, 1997.

${ }^{3}$ Brown, R., and Darrow, F., "X-34 Main Propulsion System Design and Operation," 34th AIAA/ASME/SAE/ASEE Joint Propulsion Conference and Exhibit, July 13-15, 1998.

${ }^{4}$ Meyer, C., Cannon, H., Balaban, E., Fulton, C., Maul, B., Chicatelli, A., Bajwa, A., Wong, E., "Propulsion IVHM Technology Experiment Overview," 2003 IEEE Aerospace Conference, Big Sky, MT, March 8-15, 2003.

${ }^{5}$ Balaban, E., Maul, W., Sweet, A., Fulton, C., Bajwa, A. and Chicatelli, A., Hayden, S., "Transient Region Coverage in the Propulsion IVHM Technology Experiment," The 2004 International MultiConference in Computer Science and Computer Engineering, Las Vegas, Nevada, June 21-24, 2004.

${ }^{6}$ Bajwa, A., Sweet, A., “The Livingstone Model of a Main Propulsion System,” 2003 IEEE Aerospace Conference, Big Sky, MT, March 8-15, 2003.

${ }^{7}$ Sweet, A., Bajwa, A., "Lessons Learned from Using a Livingstone Model to Diagnose a Main Propulsion System,” 2003 JANNF Conference, Colorado Springs, CO, December 1-5, 2003.

${ }^{8}$ Design-Expert 6 User’s Guide, Design-Expert ${ }^{\circledR}$ Software, Version 6, Stat-Ease ${ }^{\circledR}$, Inc., 2000. 
Public reporting burden for this collection of information is estimated to average 1 hour per response, including the time for reviewing instructions, searching existing data sources, gathering and maintaining the data needed, and completing and reviewing the collection of information. Send comments regarding this burden estimate or any other aspect of this
collection of information, including suggestions for reducing this burden, to Washington Headquarters Services, Directorate for Information Operations and Reports, 1215 Jefferson Davis Highway, Suite 1204, Arlington, VA 22202-4302, and to the Office of Management and Budget, Paperwork Reduction Project (0704-0188), Washington, DC 20503.

\begin{tabular}{|l|l|l}
\hline 1. AGENCY USE ONLY (Leave blank) & $\begin{array}{c}\text { 2. REPORT DATE } \\
\text { January } 2005\end{array}$ & $\begin{array}{c}\text { 3. REPORT TYPE AND DATES COVERED } \\
\text { Final Contractor Report }\end{array}$
\end{tabular}

4. TITLE AND SUBTITLE 5. FUNDING NUMBERS

Addressing the Real-World Challenges in the Development of Propulsion IVHM Technology Experiment (PITEX)

\section{AUTHOR(S)}

William A. Maul, Amy Chicatelli, Christopher E. Fulton, Edward Balaban, Adam Sweet, Sandra Claire Hayden, and Anupa Bajwa

\section{PERFORMING ORGANIZATION NAME(S) AND ADDRESS(ES)}

Analex Corporation

1100 Apollo Drive

Brook Park, Ohio 44142

WBS-22-794-40-56

NAS3-00145

9. SPONSORING/MONITORING AGENCY NAME(S) AND ADDRESS(ES)

National Aeronautics and Space Administration

Washington, DC 20546-0001

8. PERFORMING ORGANIZATION REPORT NUMBER

E-14948

11. SUPPLEMENTARY NOTES

Prepared for the First Intelligent Systems Technical Conference sponsored by the American Institute of Aeronautics and Astronautics, Chicago, Illinois, September 20-22, 2004. William A. Maul, Amy Chicatelli, and Christopher E. Fulton, Analex Corporation, Brook Park, Ohio 44142; Edward Balaban, Adam Sweet, and Sandra Claire Hayden, QSS Group, Inc., Moffett Field, California 94035; and Anupa Bajwa, University Affiliated Research Center, Moffett Field, California 94035. Project manager, Edmond Wong, Instrumentation and Controls Division, NASA Glenn Research Center, organization code RIC, 216-433-8917.

12a. DISTRIBUTION/AVAILABILITY STATEMENT 12b. DISTRIBUTION CODE

Unclassified - Unlimited

Subject Categories: 20, 60, 65, and 66

Distribution: Nonstandard

Available electronically at http://gltrs.grc.nasa.gov

This publication is available from the NASA Center for AeroSpace Information, 301-621-0390.

13. ABSTRACT (Maximum 200 words)

The Propulsion IVHM Technology Experiment (PITEX) has been an on-going research effort conducted over several years. PITEX has developed and applied a model-based diagnostic system for the main propulsion system of the X-34 reusable launch vehicle, a space-launch technology demonstrator. The application was simulation-based using detailed models of the propulsion subsystem to generate nominal and failure scenarios during captive carry, which is the most safety-critical portion of the X-34 flight. Since no system-level testing of the X-34 Main Propulsion System (MPS) was performed, these simulated data were used to verify and validate the software system. Advanced diagnostic and signal processing algorithms were developed and tested in real-time on flight-like hardware. In an attempt to expose potential performance problems, these PITEX algorithms were subject to numerous real-world effects in the simulated data including noise, sensor resolution, command/valve talkback information, and nominal build variations. The current research has demonstrated the potential benefits of model-based diagnostics, defined the performance metrics required to evaluate the diagnostic system, and studied the impact of real-world challenges encountered when monitoring propulsion subsystems.

\section{SUBJECT TERMS}

15. NUMBER OF PAGES

System failures; Failure analysis; Fault detection; Systems health monitoring; Aerospace safety; Safety management

17. SECURITY CLASSIFICATION OF REPORT

Unclassified

18. SECURITY CLASSIFICATION OF THIS PAGE

Unclassified
19. SECURITY CLASSIFICATION OF ABSTRACT

Unclassified 

